\title{
Article
}

\section{Building productive relationships with young people with SEBD in transition: the role of identity}

\author{
O'riordan, Zoe
}

Available at http://clok.uclan.ac.uk/12368/

O'riordan, Zoe ORCID: 0000-0001-8083-2648 (2015) Building productive relationships with young people with SEBD in transition: the role of identity. Emotional and Behavioural Difficulties, 20 (4). pp. 415-431. ISSN 1363-2752

It is advisable to refer to the publisher's version if you intend to cite from the work. http://dx.doi.org/10.1080/13632752.2015.1032108

For more information about UCLan's research in this area go to http://www.uclan.ac.uk/researchgroups/ and search for < name of research Group>.

For information about Research generally at UCLan please go to http://www.uclan.ac.uk/research/

All outputs in CLoK are protected by Intellectual Property Rights law, including Copyright law. Copyright, IPR and Moral Rights for the works on this site are retained by the individual authors and/or other copyright owners. Terms and conditions for use of this material are defined in the policies page.

\section{CLoK}

Central Lancashire online Knowledge www.clok.uclan.ac.uk

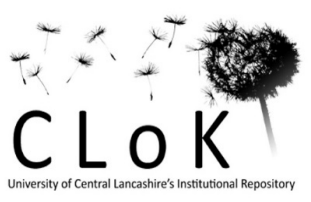


Building productive relationships with young people with SEBD in transition: the role of identity

Dr Zoe O’Riordan

School of Education and Social Science, University of Central Lancashire, Preston, UK

University of Central Lancashire, Preston, PR1 2HE

Email: zo-riordan@uclan.ac.uk 


\section{Building productive relationships with young people with SEBD in transition: the role of identity}

This paper reports a study of the experiences of school-leavers with social, emotional and behavioural difficulties (SEBD), which identified supportive relationships as a key element in the young people demonstrating resilience through this transitional period. Almost all the young people involved in the study had access to potential helpers, but few managed to establish productive relationships with them. Analysis of interviews, conducted over a 15 month period with a group of 15 school leavers, their parents and those who worked with them, suggested that barriers and facilitators to relationship development existed on two levels: institutional and individual. This paper focuses on the individual level, in which identity processes appear to play a key role. These processes are used to explain why some school-leavers built productive relationships and thrived, whilst many failed to do so, and struggled. The findings have implications for policy, practice and theory.

Keywords: social, emotional and behavioural difficulties; transition; identity; resilience; relationships 


\title{
Building productive relationships with young people with SEBD in transition: the role of identity
}

\author{
This paper reports a study of the experiences of school-leavers with social, \\ emotional and behavioural difficulties (SEBD), which identified supportive \\ relationships as a key element in the young people demonstrating resilience \\ through this transitional period. Almost all the young people involved in the \\ study had access to potential helpers, but few managed to establish productive \\ relationships with them. Analysis of interviews, conducted over a 15 month \\ period with a group of 15 school leavers, their parents and those who worked \\ with them, suggested that barriers and facilitators to relationship development \\ existed on two levels: institutional and individual. This paper focuses on the \\ individual level, in which identity processes appear to play a key role. These \\ processes are used to explain why some school-leavers built productive \\ relationships and thrived, whilst many failed to do so, and struggled. The findings \\ have implications for policy, practice and theory.
}

Keywords: social, emotional and behavioural difficulties; transition; identity; resilience; relationships

\section{Introduction}

Transitions are moments of possibility, when experiences of change allow the individual to develop in new ways, for better or worse (Dearden 2004; Smokowski, Reynolds, and Bezrucko 1999). Countless young people find leaving school a positive experience, through which they develop their independence and move towards their adult goals. However, many school-leavers with social, emotional and behavioural difficulties (SEBD) seem ill-prepared for further education, training or employment (Casey et al. 2006; Polat and Farrell 2002; Polat et al. 2001). In the long term, school leavers with SEBD experience far worse outcomes than their peers, including low levels of education, high unemployment rates and increased risk of involvement in crime or substance abuse. 
These outcomes are reported consistently across time and continents (e.g. Armstrong and Davies 1995; Zigmond 2006; Jahnukainen 2007; Hornby and Witte 2008). However, whilst group outcomes are poor, every study reports some individuals who go on to become productive, well-adjusted adults. These people demonstrate more resilience than others, and if we can identify the reasons for this we can perhaps develop better supportive practices and improve outcomes for the rest of this group.

\section{Conceptual Framework}

\section{Understandings of SEBD}

Debate persists about the origins of SEBD, with researchers arguing for the dominance of a biological, genetic, social or psychological cause (Cooper and Jacobs 2011). Some see social influences, particularly the family, as reasons for children developing SEBD, making links with “delinquent” parental activity and "unsatisfactory” parenting (Cooper 1993, 9). This idea has permeated policy, with government guidance citing a range of family-based issues as risk factors in the development of SEBD (DCSF 2008). Others consider schools as creators of SEBD as a category of need, which aims to fulfil their own need for order (Thomas and Glenny 2000).

Some conditions, notably ADHD, attract attention from those claiming bio-genetic origins (Furman 2009) though the evidence is inconclusive, and even those who are convinced of the role of genetics in the development of some types of SEBD acknowledge that they develop through interactions between the child and their environment (Cooper 2004). Social factors, such as poverty and social deprivation, are strongly associated with SEBD, though the link is seen as indirect (Fovett 2011). Temperament has been suggested as an explanation for the development of SEBD, but again the evidence is conflicting, with Olson et al. (2002) claiming that children with 
difficult temperaments are subject to increased coercive transactions within their social environment, and it is these transactions that cause antisocial behaviour in the child.

Bio-genetic and psyho-social factors influence the development of SEBD, but the relationship is not causal: the environment can increase the likelihood of developing SEBD, but it can also buffer against genetic risk factors (Bronfenbrenner and Ceci 1993). Consequently, SEBD are best understood as the result of complex interactions between a child, as a biological and psychological entity, and their environment. Therefore, research seeking to understand the experiences and actions of young people with SEBD is best undertaken using a bioecological framework (Bronfenbrenner 2001), which can to take account of the wide range of influences on them, as well as their influence on the world around them.

\section{Bioecological systems theory}

Tudge, Mokrova, Hatfield, and Karnik (2009) claim that Bronfenbrenner’s bioecological framework is much abused by researchers, who claim to be using it whilst doing little more than provide a broadly holistic view of the child or family. Later presentations of the theory make clear that a bioecological approach requires consideration of process, person, context and time (Bronfenbrenner and Morris 1998). Process refers to the proximal processes that stimulate development; person includes the nature and attributes of the individual, and their influence on their environment; context incorporates all levels of the environment, from those with which the child interacts directly, to those which only influence their worlds indirectly, such as the socio-cultural and political context. Time includes time in the child's life (development or influence over time) and the historical time they grow up in (though this could be taken as an element of the context). 
This study, therefore, involved following young people over a period of time (15 months), with reflection on their past, present and their expectations of the future. Data was collected (from the young people themselves and from those who had regular contact with them) relating to their family, social and educational context. This allowed for analysis of the individual and the processes that seemed to influence their capacity to cope with their transitions, whilst placing their experiences in context (socially, educationally and historically) and seeing them enacted over time.

\section{Resilience}

Resilience is conceived, in this study, as both a process and outcome of development. It has been defined as a "dynamic process encompassing positive adaptation within the context of significant adversity” (Luthar, Cicchetti, and Becker 2000, 543). It is not a characteristic that is inherent or attained: levels of resilience may change over time, as the individual develops or their surroundings change, and may vary according to the adversity faced.

Protective factors that facilitate normal development under adverse circumstances fall into three main categories: individual attributes, family ties and external support systems (Werner 1989). Good relationships between family members are strong predictors of resilience in relation to behavioural outcomes. A strong bond with a parent in the first year of life, and living in an environment which is high on warmth and low on criticism, in which the child has access to support and affection throughout their lives, strongly buffers the child against the effects of risks in their environment (Smokowski, Reynolds, and Bezrucko 1999). Teachers, religious ministers, peers and older friends can also provide support to children, within trusting relationships. Children who demonstrate resilience tend to form bonds with a wide 
range of supporters, with teachers being the most frequently cited source of support outside of the family in one study (Werner 1990). Young people value supporters who provide them with motivation, advice, and guidance (Smokowski, Reynolds, and Bezrucko 1999). At the heart of most research findings related to resilience are relationships: the individual's ability to form and maintain them and the benefits (psychological, emotional and practical) that they receive bring.

Within this study the young people were considered to be resilient in the face of adversity (the transition out of school) if they maintained training/education/work throughout the year, without the need for specialist interventions beyond any inherent in their placement.

\section{Identity}

Academics working in many disciplines have established an association between identity and resilience (McMurray et al. 2011; Warin 2010; Wexlera, DiFluviob, and Burke 2009). Within this research identity theory, as expounded by Burke and Stets (2009), has been used to explain how and why some of the factors mentioned earlier in this paper are associated with resilience.

An identity is not a person: an individual will possess multiple identities, since we all claim multiple roles in society (e.g. mother, friend, worker) and belong to many groups (gender-, race- and class-based; social or political) (Burke and Stets 2009). Each setting that a young person enters will have an allied identity (pupil, son, friend) with an associated set of meanings. Different identities may hold very different meanings, resulting in different aspects of the individual being highlighted in different situations. For example, a young person may hold the identity of 'friend' that is linked to meanings of loyalty, empathy and fun. The same young person may also hold an identity of pupil, 
associated with obedience and serious endeavour. The situation they are in will determine the aspects of themselves that they allow to dominate. This view of identity emphasises the social nature of its construction and enactment, and places it within a cultural context.

\section{The identity control model}

According to Burke and Stets (2009) our interactions with our environment are managed by an identity control system, which consists of four elements: the input, the identity standard, the comparator and the output. The identity standard is the set of meanings associated with an identity. When there is input from the environment the comparator compares the way an individual perceives themselves to be seen in a situation to the identity standard, which contains the way they wish to be seen. If the two do not match, the individual will attempt to adjust the meanings in the situation (by modifying their behaviour) so that they conform to the identity standard: this is the output. In doing so they change the environment, as it responds to the change in them, and the cycle begins again. This cycle operates continuously: consciously or unconsciously we perpetually compare the meanings contained in our identity standard with the feedback we receive from our environment, and behave accordingly.

The aim of the identity control system is identity verification. This is achieved when the perceived meanings in a situation correspond with those contained in the identity standard: when environmental feedback tells us we are who we think we are. Identity verification results in feelings of well-being; non-verification causes stress (Zanna and Cooper 1976, cited in Burke and Stets 2009). Processes of identity control expend considerable energy, so we develop “opportunity structures” to maximise the chances of us experiencing verification (Swann 1983, 36). This is done by expressing 
who we are in our appearance (dress, mannerisms, speech patterns, etc.); choosing to associate with people and in situations where our identity is most likely to be verified, and by changing the opportunity structure using "interpersonal prompts": changing our behaviour to get others to treat us in a way that is consistent with our identity (Burke and Stets 2009, 74). These opportunity structures usually ensure that discrepancies between environmental input and our identity standard are small, minimising the energy needed to achieve verification. However, there are times when a large discrepancy occurs, which usually indicates that there has been an "interruption" to the identity. The most significant interruption for the purposes of this study is the "broken loop", in which a major life-change means that an identity no longer exists (Burke and Stets 2009, 77). Young people leaving school lose a number of identities associated with that place: their role as pupil and their established identities within their school-based peer groups evaporate as they move into new institutions and meet new people. The interruptions may result in the development of 'better' identities, which are verified within the changed context (for example, the pupil who struggles with the academic demands of school, but claims a more positive identity as a vocational learner). But the initial move is likely to cause stress and demand considerable energy, as new identities and effective control systems are developed. Burke and Stets (2009) propose that a key source of the energy needed is self-esteem.

\section{Identity verification and self esteem}

Self-esteem is a difficult concept, which in spite of attracting considerable controversy has proved remarkably resilient, both in research and practice (Mruk 2006). Some follow James (1890/1983) and view it as a feeling of competence, whilst others see it as an attitude: the belief that one has worth (Baumeister, Smart and Boden 2003). Both 
perspectives have problems associated with them, and Mruk suggests self-esteem is more constructively viewed as a feeling of both competence and self-worth (Mruk 2006). Burke and Stets (2009) largely side-step this debate, describing self-esteem as a reservoir of energy, which is the product of identity verification.

Experiencing identity verification tops up the energy contained in the selfesteem 'reservoir', whilst non-verification diminishes it. It is debateable whether this reservoir of energy is 'self-esteem' in the sense that the term has been more commonly used, but the concept of energy is useful. It may be that the positive emotions an individual experiences when they feel verified are the key to them being able to adjust to identity-challenging situations. Barclay and Kiefer (2014) claim that positive emotions increase energy levels and performance, and result in adaptive behaviours and constructive approaches to organisational change. Whether the energy contained in the reservoir is defined as self-esteem, or is simply the result of positive emotions experienced as a by-product of verification, it does help to explain variation in young people’s capacity to cope with change and make the transition out of compulsory education. For the purposes of this paper, the concept of an energy reservoir will be accepted, as it is supported by the data, but the relationship of the reservoir to the poorly defined and highly contested concept of self-esteem remains undetermined.

The effects of persistent verification or non-verification on the reservoir are cumulative. Where an individual has obtained persistent verification and the levels are high, they are able to cope with difficult (non-verifying) situations in the short-term to gain long-term benefits (Burke and Stets 2009). In terms of transition, they are better placed to cope with the broken loop interruption to school-based identities necessitated by leaving school: they have the energy reserves needed to develop control systems for their new identities. However, if a person has experienced consistent non-verification 
their reservoir levels will be low. Faced with the same situation, they are more likely to find themselves with insufficient energy to develop a control system to manage a new identity, and withdraw from the situation (for example by dropping out of college). Selfesteem energy, gained through identity verification in one context, allows individuals to persevere in other, identity-challenging situations (such as the transition out of compulsory education).

Identity verification usually happens within social interactions, so the ability of the young person to find people with whom they can develop verifying relationships may be a key element in resilience. However, understanding a young person’s identity requires a holistic approach that recognises the bi-directional and contextualised nature of the meanings associated with their identities, and the relationships they are enacted within. Thus, the element of this research project reported in this paper is built upon bioecological systems theory, with a particular focus on the influence of identity processes on the demonstration of resilience.

\section{The Research}

\section{Overview}

The research aimed to gain an understanding of the transitional support given to the school-leavers and the way they engaged with it, and to identify more promising approaches to helping them. It involved an in-depth analysis of the experiences of a group of young people with SEBD leaving special school (residential and day) and mainstream school.

Fieldwork was conducted between April 2009 and October 2010. 


\section{Methods}

A qualitative longitudinal study was conducted, in which a group of school-leavers with SEBD were followed for up to 15 months after they left school. From an initial sample of 15, meaningful post-school data was collected for 13 participants, of whom:

- $\quad$ nine were leaving special school (six day pupils, three residential);

- two of the residential leavers continued to live at the school whilst attending offsite, post-compulsory educational provision;

- four were leaving mainstream school (including two girls, all other participants were boys).

In each of the schools all young people who were leaving school in September 2009 were invited to participate. In the mainstream school all pupils who were on the school's SEN register (that is all those who were Schools Action, Schools Action Plus or Statemented), where the principle concern was behaviour, were approached. There were no girls leaving either of the special schools in the year of this study.

While the young people were still at school data was collected from them on their histories and their support networks. They were then interviewed up to three times in their first post-school year. Their parents were also interviewed (where possible), along with many of the people who worked with them. From the data a case study was developed for each participant's transition, detailing their difficulties, history and postschool experiences. The facts of the young person's life were supplemented with information gained through a thematic and narrative analysis of the data, which identified the main influences on their transitions. In this way a full and rounded view 
was developed of each participant as an individual, contained within their family and wider social world, and the way professionals supported them.

\section{Ethics}

All of the people who were interviewed for this study were vulnerable in some way. The young people's vulnerability was the most obvious, because of their age and their special educational needs. However, many of the parents had difficulties of their own, in the present or past, which increased their vulnerability (mental health problems, drug or alcohol addiction or abuse, domestic violence, lack of literacy). The workers, too, were vulnerable, since they were exposing their practices to criticism, with the potential that feedback to their employers might damage their careers. Therefore the ethical implications of every decision made about the research process were of paramount importance.

Ethical research guidelines (BERA 2004) were followed in relation to all aspects of this project. As well as ensuring informed consent was given repeatedly throughout the course of the study, maintaining confidentiality and ensuring anonymity, methods were devised that allowed the interviewees a high degree of control over the direction and pacing of the interviews, and an effort made to ensure they were pleasant experiences. In some cases this was by meeting school-leavers in comfortable environments, such as coffee shops, or allowing a parent to say what they needed to, even if that meant they answered the questions they wanted to, rather than those they were asked; in others by letting the professionals know that I had worked in similar settings and understood the conflicts and challenges they faced.

Collaborative methods were used to collect data in the first interviews with the young people, before they left school. A life grid, a simplified version of one used by 
Wilson et al. (2007), was filled out as the interview progressed in full view of the pupil. It was then used to create a biographical narrative that was verified with the young person. Support networks were mapped using a spider diagram, completed with the pupil. As previous researchers have noted (Parry, Thomson, and Fowkes 1999; Wilson et al. 2007) this created a collaborative atmosphere, and allowed the young people to see what was being written down about them, to control the pace and content of the interview, to move between time and place in telling their stories, and to raise sensitive issues if and when they felt ready.

The young people were also given control over who was interviewed in relation to them: the schools acted as gate-keepers controlling access to the young people, but the young people acted as gate-keepers to their parents and workers, who were only contacted on the school-leaver's consent. The young people's school-held files were not viewed, as these files often contain highly personal information that would have coloured my view of the young people and disempowered them within the research. This meant that there was no access to information about the labels given to the young people beyond what they, or those who knew them, offered. However, giving the young people control over the information I had access to supported the development of trusting relationships, which in turn helped me to maintain contact with them over the period of the study.

At the same time as allowing the interviewees to freely express themselves in a safe and comfortable setting, it was important to maintain the boundary between researcher and interviewee, and not become their counsellor or advocate. Young people were informed of the limits of the confidentiality that could be guaranteed to them because of their legal status as children. 
Pseudonyms have been used throughout this paper, to respect all the participants’ rights to privacy and confidentiality.

\section{Analysis}

The cases were analysed to different levels depending on the amount of data available. Keeping track of young people with SEBD for over a year is challenging, and some dropped in and out of the research, whilst contact was lost permanently with others. The four levels of analysis used were based on Hernadi’s (1987) triangle (explication, explanation, exploration) and were:

(1) Explication: the description of what happened to the school-leavers during the study period). All fifteen cases were analysed to this level.

(2) Explanation: focussing on each individual's contextualised transition, based on a thematic and narrative analysis of data from all sources. There was sufficient data to analyse twelve cases to this level.

(3) Exploration through the use of Bronfonbrenner's person-process-context-time model to facilitate thematic cross-case analysis, conducted using ten cases.

(4) Further exploration: all informants' narratives were analysed, focusing on selfperceptions and perceptions of how others saw them. Cases where the young person's expectations and view of themselves differed from, or agreed with that of those working with them were identified, and the impact this may have had on their relationships with supporting professionals was explored. It was possible to analyse eight cases at this level.

\section{Post-school experiences}

The participants' post-school experiences varied widely. They engaged in a range of 
academic and vocational courses, with differing levels of success. Five of the fifteen participants were generally successful in their first year out of school (although one was still attending his residential special school on an extended placement). They completed their courses with minimal problems or were engaged in work for most of the year, and were working towards long-term goals. Three completed their courses, but did not achieve their potential (according to their workers). Four were engaged in educational activities throughout the year, but changed course once or more, and one was NEET (Not in Education, Employment or Training) all year. One of the two participants that there was very limited data on had left his grandparents' home and 'gone to social services' before I was able to interview him; the other was NEET throughout the year. A significant proportion of the participants faced problems at home. Four left home during the year: two moved into hostels for homeless young people, and two others were cared for by social services. Another participant found the move from residential school back into home so difficult that he threatened suicide on a number of occasions.

\section{Main influences on transitions}

A range of factors influenced the young people’s transitions, including:

- personal drive, goal-motivation and perseverance, and being perceived as likeable by those working with them;

- families who were able to provide them with all forms of support (esteem, emotional, practical and informational), or access to this support from other sources;

- strong communication channels between the professionals working with them;

- post-school placements that met their emotional and social as well as educational needs; 
- productive relationships with the people working with them, which were most likely to be formed in institutions that supported their development.

(O’Riordan 2011)

One of the dominant influences on the post-school experiences of the school-leavers studied was the relationships they formed with their professional supporters. Those who adjusted well to life outside school built constructive relationships, in which they felt secure and took the help available to them. Those who struggled through their first year after school did not.

\section{The role of identity processes in transition}

Almost all the young people involved in this study had access to professionals who could have improved their transitional experiences, so what distinguished those who built successful relationships from those who did not? This question is answered by the presentation of four cases, illustrating the consequences of the participants experiencing verification or non-verification in their post-school context, showing how some benefitted from not experiencing the broken loop interruption to their identity, and one who prioritised relationships and identities that decreased his chances of success in education.

\section{Tom}

Tom was one of only two participants who appeared to have their identities verified in their relationships with those who worked with them. He was one of the most challenging young people in the sample, with a complex history and home life, and yet he achieved all he set out to in his first year out of school.

Although diagnosed with ADHD, when Tom talked about his SEBD he described it as a 
consequence of his circumstances, rather than an element of his 'self'. He attributed his poor behaviour to the emotional abuse he had been subjected to by his mother and sisters. When he moved in with his father he believed things would be easier for him: 'cos I couldn't learn before, you know, with all the stress and that, but now I can, I just need a bit more time [an extension to his special school placement] to make up for what I've missed'. He had always been keen to learn, he said, but had been unable to whilst dealing with a difficult home situation.

Although he saw the source of his problems as external to himself he still took responsibility for his actions: he accepted his mistakes and determined to learn from them. For example, he was made homeless within a few months of leaving school and moved into a hostel. At first, when he got his benefit money he would 'blow it all, on nothing really, and then have nothing left for food and stuff. Did that a few times, then I thought, can't go on like this!' With the help of his hostel worker he began to budget his money, so he had enough for everyday essentials and some to spend on clothes and music. As he put it: 'I was a bit stupid before, but I've got the hang of it now.' The problem in this case (from Tom's point of view) was not fecklessness, but lack of knowledge and experience, and his response was to find someone to help him.

Tom's head teacher, hostel key worker and college tutor all seemed to share this view of Tom and his problems. They all commented on how he would make mistakes (rather than perform deliberate acts of disruption or defiance), and that he would never try to deny his actions, learning from them instead. Thus, the identity he held for himself, as someone whose problems stem from external influences (his troubled home life or lack of experience or knowledge) was verified by those who worked with him.

When Tom left his dad's home and moved into the hostel he stopped attending college for a few weeks. He and his college tutor both said that he could not cope with 
college whilst undergoing such an upheaval. If we view this process through the lens of identity theory, the move out of his father's home created a 'broken loop' interruption to his 'home' identity: he was no longer a dependent child living at home. He needed to create a new 'home' identity and control system. The resources required to support this change of identity meant that there was not enough energy to continue enacting his 'student' identity, so he withdrew from the college situation and focussed on home. Once his home identity stabilised he was able to return to college, as he then had the resources to maintain his 'student' identity.

His college tutor's acceptance of the situation, and understanding of Tom's needs led to her giving him the time he needed to repair the broken loop, whilst providing further verification for his identity (it was not his fault he was not attending college; it was circumstances). Being verified in both his college and his hostel may have contributed to Tom's overall level of confidence and optimism about the future. He successfully completed his course, found a suitable course to progress onto, and had plans to leave the hostel when he was old enough (and ready) to live on his own.

\section{Andrew}

Andrew experienced one of the most difficult transitions of the young people studied. He struggled to settle into home life having been in a residential school and was unemployed throughout the year. He took to staying out late or not going home at all, was beaten up while out and was aggressive towards his family. His mental health suffered and he threatened suicide on a number of occasions.

Andrew was one of three of the participants who seemed not to have their identities verified by those who worked with them. Before he left school, Andrew was optimistic about his future: 'look out world, I'm comin' at ya!' He projected an identity in which 
he was a young man leaving the shelter of school and ready, even eager, to take his place in the adult world. In my first interview with him Andrew told me that he had ADHD for which he was medicated. This was the only time he talked about his SEBD; he never mentioned his other diagnosis of Asperger's. It did not seem to be a part of his self that he considered important, or wanted to draw attention to.

When he left school he refused to take up the college place he was offered (further basic skills training), saying he had 'done enough learning'; he wanted to work. However, there was little employment available and he was unable to get a job. He was supported by a Connexions worker and a learning disability officer from the job centre. The opportunities they suggested to him were all basic skills training, and were all for young people with learning difficulties.

This created a clash between the identity of young adult that Andrew was claiming, and the identity of person with special needs being reflected back to him. He spent his time helping out at the bus station, which he described as his 'work'. He had a shift timetable he adhered to rigidly (on one occasion when I visited him he was very upset because he thought I was coming the next day, and he had to go to 'work'). The bus drivers and other workers at the depot accepted his help, and treated him as a junior colleague, according to his mum. At the same time he began socialising with a group of 'boy racers' (his mum’s description), and staying out late or not coming home.

These two activities would have provided opportunities for verification of his 'adult' identity. Within the bus depot he was able to claim the adult role of worker, albeit without pay. With the 'boy racers' he could assert his independence from his parents, and associate with young men who possessed what may be the ultimate symbol of adulthood and freedom in our society: the car. It may be that it was the verification he received in these contexts that provided him with the energy resources to persevere 
with the non-verifying relationships he had with his professional supporters. Ultimately, his perseverance gained him a place in a job search club, where he was just another claimant: his 'adult' identity was finally verified. However, this did not happen until he had been out of school for a year.

Ben

Andrew refused to engage with activities which did not verify the identity he was claiming and found alternative ways of gaining verification. In contrast, Ben seemed to use the verification he received outside of the education system to provide him with the self-esteem energy he needed to maintain his placement in a non-verifying college placement.

Ben talked about his ADHD in every meeting I had with him. It seemed to be a prominent part of his understanding of himself. He saw it as a reason, but not excuse for his poor behaviour at school and at college. He felt that it made learning harder, and the classroom a more difficult place to be for him than his peers. He was keen to take responsibility for his actions, and accepted that he had to try to conform to class rules, but he felt he needed help in doing this. He did not feel he had ever received enough help with his problems, and attributed much of his improvement whilst at school to his own efforts. He expressed the view that he had worked hard to improve his behaviour, and that this should be recognised.

In college he did not receive this recognition. Without a copy of his Statement they would not provide any support or flexibility. When he 'muttered' at his tutor in his college classes he was disciplined, as his tutor found this behaviour unacceptable. Ben, however, saw muttering as evidence of his progress: 'I'm not throwing chairs or yelling at her like I used to when I was younger'. Whilst he was at school he was given extra time 
for homework and exams; in college he was marked down when his assignments were late, although he believed he had done well to get them done when he did: 'I thought I was doing ok. I mean, I did 'em all, and was only a few days late, but they didn't care.'

The hostility in Ben's relationship with his tutor and other members of staff at college (which seemed to be mutual) can be seen as a result of the gap between his identity standard and the version of himself that Ben felt they presented him with. Whilst he saw himself as an able student, doing his best, who needed some lee-way to enable him to achieve, they saw him as a disruptive and unmotivated student who would not meet their deadlines. Viewed in this way, the animosity Ben felt towards his tutor was his emotional response to the non-verification he was experiencing. And it is likely that a similar process was producing anger and frustration in his tutor, as he challenged her 'competent teacher' identity.

It might be expected that Ben would withdraw from this non-verifying situation at college. However, he had close and supportive relationships with his family. He was very close to his maternal grandmother (who lived in the same building as the rest of his family). At times he worked alongside his step-father, and he had an open and trusting relationship with his mother. He also had strong friendships, and his friendship group increased during his time at college. These relationships may have provided him with the verification he needed to maintain the energy levels in his self-esteem reservoir, and persevere in the non-verifying context of college. However, the effect of his failure to gain verification at college throughout the year drained his reservoir, so that he lost confidence in his ability to succeed in an academic context, and said: 'I can't do it, it's just too hard'.

\section{Simon}

Simon was one of two participants who did not experience the broken loop interruption 
to their identity when they left school. He attended college one day a week in his final year at school and developed a good relationship with the tutor, Brian. When he left school he attended a course run by Brian. They developed a particularly strong bond through a process of mutual verification.

Simon presented himself as a hard-working, competent young man. He was friendly and sociable, and talked comfortably with adults as equals. His identities were verified in his relationship with Brian in several ways. As a student he received praise and reward (in the form of good marks) for his work, and the Brian considered Simon's success to be the result of his own efforts. At the same time Brian offered Simon verification as an individual by choosing to spend time with him out of class (playing chess with him, eating with him). In this way both his role and person identities received support from his tutor. Brian, meanwhile, gained verification from Simon who not only achieved highly on the course but also attributed his success to the tutor's support. The unit manager, who valued the work Brian was doing, expressed the view that he was the only person in the department who could do it, thereby providing verification for his teaching identity. These processes created a bond between Simon and his tutor which went beyond the limits of the classroom, and the duration of the course: Brian intended to continue to support Simon when he moved on to a new course within the same college, helping him to get to know the tutors and ensuring they understood his needs. Simon was keen to come back and see Brian once he had left the course.

In 'mutual verification contexts' (Burke \& Stets 2009, p.86), such as that described between Simon and Brian, each individual's verification process serves to support the other, which creates a bond that helps to provide continuing mutual verification. This created a relationship that was deeper and more durable than would be 
expected between most tutors and their students on a one year course. Brian and Simon were both prepared to continue to invest in the relationship after the course finished suggesting they were each getting something out of it (identity verification) that was not directly related to their roles as teacher and student. This relationship could be criticised for breaching professional boundaries, however as all interactions took place within the college, during the working day, it is probably better seen as a tutor providing social and emotional, as well as educational support, for a student and feeling rewarded by his achievement. Those who work with learners with SEBD often feel the need to support their socio-emotional well-being, compensating for the inability of their families to fulfil all their needs (Broomhead 2013).

\section{Michael}

Michael had good relationships with the professionals working with him, and yet failed to maintain a placement in his first post-school year. He contradicts the theory presented so far that positive relationships with helpers, developed through processes of verification support successful transition. However, this can be explained using identity theory, since the main reason for Michael's failure to maintain a placement was his prioritisation of his social identity over all others.

Michael's and Connexions worker, Mark, had a warm relationships. They had known each other for some years and Mark genuinely liked Michael, and compared him to himself when he was young. Michael was a Christian, who presented himself as a very caring young man, and Mark shared this view of him and encouraged the other young people he worked with to see through Michael's 'odd' behaviour and befriend the kindly individual behind it. As such, he was not only providing verification for Michael's identity directly, but also increasing the possibility that Michael would be 
verified by his peers. Most of the tutors and trainers who worked with Michael also seemed to like him. He achieved, initially, on their courses and received praise for his work, but it is clear that none of these people were providing Michael with verification of an identity he valued as he walked out on these relationships (and courses), avoiding Mark as he did so.

Michael said he left his first college course because he had missed a few weeks and was unable to catch up with the work. However, his tutor was confident that he could easily have caught up had he wanted to: he had left to go to the training centre his girlfriend attended. This theory is supported by the fact that when the girlfriend left that training centre and moved to another, Michael followed her. His educational/career decisions were being led entirely by his desire to be with her.

Michael adopted a ‘hero’ type identity in his relationship with his girlfriend. When he talked about her, he stressed how she needed him, how he was 'there' for her, and told of his acts of kindness towards her. He claimed she had been 'sectioned' before, and that he was going to take care of her so that she no longer suffered from the anxiety and distress that had plagued her. By moving placement to stay with her he was ensuring that this identity, in which he was needed, could be verified. However, in doing so he was prioritising his boyfriend identity (and the meanings associated with it) over all others. Thus, it can be described as an “over-controlled” identity (Burke and Stets 2009, 78), which took so much energy and resources to maintain that his other identities were neglected. His workers could not help him with the transition process because he was over-investing in his other identity, which was not relevant in their work with him.

Michael's relationships with his peers had been his main source of problems at school, and this may be why he prioritised verification in this area outside of school. He 
split up with his girlfriend after around six months, and not long after that he left home. Although he claimed his mother threw him out, he also said that he had a lot of friends who lived at the hostel, who he knew before he moved there. It may be that his need for verification from his peers was greater even than his need to sustain his relationship with his mother, and this contributed to his decision to leave home and move into the hostel.

\section{Identity and resilience in transition}

Overall, positive relationships with professional supporters facilitated smooth transitions and helped the participants cope with difficulties they faced. Using identity theory to analyse the cases reveals that processes of identity verification seem to underpin the development of constructive relationships between the young people and the professionals working with them. Opportunities for identity verification increased the strength of these relationships, and this supported smooth transitions out of school. Few of the young people had access to verifying situations in all the settings with which they engaged, but when they did (as in Tom's case) the relationships they built in these settings were able to facilitate positive outcomes in highly challenging situations.

Some of the school-leavers were able to persist in non-verifying situations, whilst others withdrew from them. Their capacity to persevere in difficult situations can be attributed to them receiving enough verification in other settings to keep their energy reservoir topped up. Others rejected non-verifying educational situations, and used other contexts to verify the identity they sought to claim. One participant had an identity (boyfriend) that was so tightly controlled that all others (student, son, brother, friend) were sacrificed to ensure it was verified.

To maximise their chances of success through the year, the young people needed to: 
- build constructive relationships with their professional helpers, which was most likely to be achieved when the participant's identity was verified in the context of the relationship;

- maintain a balance between the multiple identities they held - using those that were verified to provide them with the energy resources to persist in situations where they were not verified;

- prevent any of their identities from drawing so much from their energy reservoir that other identities suffered.

The ability to create or find opportunities for identity verification that are socially acceptable may be a key process in resilience. It has been claimed that young people who feel unable to make positive choices (or to find opportunities for verification of positive identities) in their lives will find people to support them in making negative ones (Thomas et al. 2002). It is the verification that is important to the individual, and any form of verification makes them feel good. Where young people involved in this study had access to positive ways of having their identities verified they used them, but if they did not receive verification in these ways they found other ways of ensuring they were verified.

\section{Discussion}

This paper reports the findings of a very small scale study, conducted in a small geographical area over a relatively short period of time, so it is not possible to make major claims from the results. The implications discussed in this section are therefore areas that warrant further research, rather than definitive explanations or theories.

A number of researchers have made the link between resilience and identity (McMurray et al. 2011; Warin, 2010; Wexlera, DiFluviob, and Burke 2009; Wigley et 
al. 2011) but this study suggests that identity verification may by the process underlying this association. The identity verification process helps to explain how the presence of supporters in young people's lives helps them to cope with challenging situations where they are unsupported. By conceiving the consequences of verification as a well of 'energy' that can be drawn on in non-verifying situations and topped up by verification, Burke and Stets (2009) offer a process that may underpin resilience.

Smokowski, Reynolds, and Bezrucko (1999) descriptions of the way supporters help young people facing adversity (motivation, advice, guidance) are also actions that may serve to verify the young person's identity. Effective motivation comes from an understanding of a child's skills, talents and interests; useful advice can only be offered by someone who understands the problems being faced, and guidance on how to cope in dangerous situations is only useful if it is based on the young person's understandings of themselves and the situation they are in. These actions would all provide the young person with the feeling that they are understood and valued for who they are: they will feel verified.

Many of the factors associated with resilience are related to having strong, supportive relationships, within and beyond the family, and a sense of belonging (to religious organisations, for example) all of which would provide the young person with opportunities for verification of pro-social identities. This verification will provide them with sufficient 'energy' to allow them to risk rejection in new environments, and they are more likely to be open to forming relationships with others, where they may receive further verification. If they are not verified within this new environment then the constant top-up to their energy reservoirs that they receive at home, or from other existing relationships, will allow them to persevere with this difficult situation, until they are verified or move on. Thus, identity processes offer insight into the way the 
presence of supportive relationships in young people's lives may help them to overcome adversity, even when they have no support in a particular context (such as school). This places identity processes and relationships at the heart of resilience.

Identity verification processes and the energy they provide can also explain why the factor-based influences on transition, mentioned earlier, affected the young people's transitions. 'Families, or others, who were providing their children with all forms of support (esteem, emotional, practical and informational)' could also be providing them with verification of positive identities. 'Strong communication channels between the professionals working with them' would increase the chances of any new workers coming into the young person's life having an understanding of them - the more they know about the young person's self-perceptions the greater the chance that they will be able to verify positive aspects of them. 'Post-school placements that meet their emotional and social as well as educational needs' are likely to cater for the whole young person, and this would include providing them with supportive, understanding (and so potentially verifying) relationships. 'Productive relationships were most likely to be formed in institutions that supported their development': this makes sense if the worker’s identity verification needs are taken into account. Relationships with young people with SEBD can be difficult to establish and maintain, which is likely to draw on the worker's 'energy' reservoir. Therefore, the worker is going to need verification of this element of their worker identity if they are to have the energy to persist when these young people challenge their competence.

\section{Conclusion}

Transition opens a "window of opportunity” for change to young people: a change of identity or life trajectory, for better or worse (Masten et al. 2004, 1091). The cases 
discussed in this paper seem to suggest that identity verification processes may lie at the heart of the young people's ability to form productive relationships with helpers, and to cope with the challenge of the transition out of compulsory education. The sample used in this research was too small and non-representative for it to be possible to make claims beyond this study, but the findings warrant further investigation. Children and young people go through many institutional transitions in the course of their school lives, not just between schools, but also between year groups, and each transition offers the potential to help them to construct identities that 'fit' with the environment, and so experience verification.

Children and young people with SEBD often have school-oriented identities that are antisocial and do not facilitate learning; use of these identities results in poor outcomes in the long term, both within and beyond education, leading to unacceptable costs on an individual and societal level. It is possible that through supportive, identityfocussed practices, practitioners may be able to help these young people to develop more constructive identities in the short term, and so place them on happier, more productive pathways in the longer term. 


\section{References}

Armstrong, D. and P. Davies. 1995. “The transition from school to adulthood: Aspiration and careers advice for young adults with learning and adjustment difficulties.” British journal of special education. 22 (2): 70-75. doi:10.1111/j.1467-8578.1995.tb01326.x.

Barclay, L.J. and T. Kiefer. 2014. “Approach or Avoid? Exploring Overall Justice and the Differential Effects of Positive and Negative Emotions.” Journal of Management 40 (7): 1857-1898. doi: 10.1177/0149206312441833.

Baumeister, R. F., J.D. Campbell, J.I. Krueger, and K.D. Vohs. 2003. “Does high selfesteem cause better performance, interpersonal success, happiness, or healthier lifestyles?” Psychological Science in the Public Interest, 4 (1): 1-44. doi:10.1111/1529-1006.01431.

BERA 2004. Revised ethical guidelines for ethical research. Slough: British Educational Research Association.

Bronfenbrenner, U. 2001. "Growing chaos in the lives of children, youth, and families: How can we turn it around?” In Making human beings human: Bioecological perspectives on human development edited by U. Bronfenbrenner. 2005. 185197. London: Sage.

Bronfenbrenner, U. and S.J. Ceci. 1993 "Heredity, environment and the question of "how": A first approximation.” In Making human beings human: Bioecological perspectives on human development edited by U. Bronfenbrenner. 2005. 174184. London: Sage.

Bronfenbrenner, U. and P.A. Morris. 1998. “The ecology of developmental processes.” In The Handbook of Child Psychology, Vol. 1: Theoretical models of human development. edited by W. Damon and R. M. Lerner. 5th ed. 993-1023. New York: Wiley.

Broomhead KE. 2013. “'Going the extra mile': Educational practitioners compensating for perceived inadequacies in the parenting of children with behavioural, emotional and social difficulties (BESD).” Pastoral Care in Education, 31 (4): 309-320. doi: 10.1080/02643944.2013.835856

Burke, P. J. \& J.E. Stets 2009. Identity theory. New York: Oxford University Press. 
Casey, L., P. Davies, A. Kalambouka, N. Nelson, and B. Boyle. 2006. “The influence of schooling on the aspirations of young people with special needs.” British Educational Research Journal 32 (2): 273-90. doi:10.1080/01411920600569214.

Cooper, P. 1993. Effective Schools for Disaffected Pupils. London. Routledge.

Cooper, P. 2004. Biology and behaviour: the educational relevance of a biopsychosocial perspective. In Handbook of emotional and behavioural difficulties, edited by P. Clough, P. Garner, J.T. Pardeck \& F. Yuen. 105-121. London: Sage.

Cooper, P. and B. Jacobs. 2011. From Inclusion to Engagement: Helping Students Engage with Schooling through Policy and Practice. Chichester: WileyBlackwell.

Dearden, J. 2004. "Resilience: A study of risk and protective factors from the perspective of young people with experience of local authority care.” Support for Learning 19 (4): 187-92. doi: 10.1111/j.0268-2141.2004.00346.x.

DCSF. 2008. The Education of Children and Young People with Behavioural, Emotional and Social Difficulties as a Special Educational Need. London: The Stationery Office.

Fovet, F. 2011. “Towards a new construct of social, emotional and behavioural difficulties.” Emotional and Behavioural Difficulties 16 (3): 249-262. doi:10.1080/13632752.2011.595089.

Furman, L. (2009). “ADHD: What do we really know?” In Rethinking ADHD, edited by S. Timimi and J. Leo. 21-57. Basingstoke: Palgrave Macmillan.

Hernadi, P. 1987. "Literary interpretation and the rhetoric of the human sciences.” In Rhetoric of the Human Sciences, edited by J. S. Nelson, A. Megill and D. N. McCloskey. 263-275. Wisconsin: University of Wisconsin Press.

Hornby, G. and C. Witte. 2008. "Follow-up study of ex-students of a residential school for children with emotional and behavioural difficulties in New Zealand.” Emotional and Behavioural Difficulties 13 (2): 79-93 doi:10.1080/13632750802027598.

Jahnukainen, M. 2007. "High-risk youth transitions to adulthood: A longitudinal view of youth leaving the residential education in Finland." Children and Youth Services Review. 29: 637-54. doi: 10.1016/j.childyouth.2007.01.009. 
James, W. (1983). The principles of psychology. Cambridge, MA: Harvard University Press. (Original work published 1890).

Luthar, S.S., D. Cicchetti, and B. Becker 2000. "The construct of resilience: A critical evaluation and guidelines for future work.” Child Development 71 (3): 543-62. doi: 10.1111/1467-8624.00164.

Masten, A. S., K.B. Burt, G.I. Roisman, J. Obradovic, T.D. Lang, and A. Tellegen. 2004. "Resources and resilience in the transition to adulthood: continuity and change.” Development and Psychopathology 16: 1071-1094. doi:10.10170S0954579404040143.

McMurray, I., H. Connolly, M. Preston-Shoot, and V. Wigley 2011. "Shards of the old looking glass: restoring the significance of identity in promoting positive outcomes for looked-after children.” Child and Family Social Work. 16 (2): 210218. doi:10.1111/j.1365-2206.2010.00733.x.

Mruk, C. J. 2006. Self-esteem: Research, Theory, and Practice: Toward a Positive Psychology of Self-esteem. New York: Springer.

O'Riordan, Z. 2011. "Living in the 'real world': the experiences and support of schoolleavers with social, emotional and behavioural difficulties”. Emotional \& Behavioural Difficulties, 16 (3): 303-316. doi: 10.1080/13632752.2011.595097.

Olson, S.L., J.E. Bates, J.M. Sandy, and E.M. Schilling. 2002. “Early developmental precursors of impulsive and inattentive behaviour: from infancy to middle childhood.” Journal of Child Psychology and Psychiatry, 43 (4): 435-447. doi:10.1111/1469-7610.00035.

Parry, O., C. Thomson and G. Fowkes. 1999. "Life course data collection: qualitative interviewing using the life grid.” Sociological Research Online, 4 (2) http://socresonline.org.uk/4/2/parry.html.

Polat, F. and P. Farrell. 2002. "What was it like for you? Former pupils' reflections on their placement at a residential school for pupils with emotional and behavioural difficulties.” Emotional and Behavioural Difficulties 7 (2): 97-108. doi:10.1177/1363275202007002004.

Polat, F., A. Kalambouka, W.F. Boyle, and N. Nelson. 2001. Post-16 transition of pupils with special educational needs. London: Department for Education and Skills. 
Smokowski, P.R., A.J. Reynolds, and N. Bezrucko. 1999. "Resilience and protective factors in adolescence: An autobiographical perspective from disadvantaged youth.” Journal of School Psychology, 37 (4): 425-48. doi:10.1016/S00224405(99)00028-X.

Swann, W. B. Jnr. 1983. "Self-verification: Bringing social reality into harmony with the self.” In Psychological Perspectives on the Self edited by J. Suls and A. Greenwald. 33-66. Hillsdale, NJ: Erlbaum.

Thomas, G., and G. Glenny. 2000. Emotional and behavioural difficulties: bogus needs in a false category. Discourse: studies in the cultural politics of education, 21(3), 283-298. doi:10.1080/713661165

Thomas, R., J. Bell, J. Holland, S. Henderson, S. McGrellis, and S. Sharpe. 2002. “Critical moments: choice, chance and opportunity in young people's narratives of transition.” Sociology, 36 (2) 335-354. doi:10.1177/0038038502036002006.

Tudge, J. R. H., I. Mokrova, B.E. Hatfield, and R.B. Karnik. 2009. “Uses and misuses of Bronfonbrenner's biolecological theory of human development.” Journal of Family Theory and Review, 1(4): 198-210. doi:10.1111/j.17562589.2009.00026.x.

Warin, J. 2010. Stories of self: Tracking children's identity and well-being through the school year. Stoke-on-Trent: Trentham Books.

Werner, E. E. 1989. "High-risk children in young adulthood: a longitudinal study from birth to 32 years.” American Journal of Orthopsychiatry, 59 (1): 72-81. doi:10.1111/j.1939-0025.1989.tb01636.x.

Werner, E. E. 1990. “Protective factors and individual resilience.” In Handbook of Early Childhood Intervention, edited by S. J. Meisels and J. P. Shonkoff. 115132. Cambridge: Cambridge University Press.

Wilson, S., S. Cunningham-Burley, A. Bancroft, K. Backet-Milburn, and H. Masters 2007. "Young people, biographical narratives and the life grid: young people’s accounts of parental substance used.” Qualitative Research. 7 (1): 135-151. doi:10.1177/1468794107071427.

Wexlera, L. M., G. DiFluviob, and T.K. Burke 2009. "Resilience and marginalized youth: Making a case for personal and collective meaning-making as part of resilience research in public health.” Social Science and Medicine. 69 (4): 565570. doi:10.1016/j.socscimed.2009.06.022. 
Zigmond, N. 2006. “Twenty four months after high school: Paths taken by youths diagnosed with severe emotional and behavioural disorders.” Journal of emotional and behavioral disorders, 14 (2): 99-107. doi:10.1177/10634266060140020601. 